\title{
CardioGxE, a catalog of gene-environment interactions for cardiometabolic traits
}

Laurence D Parnell, Britt A Blokker, Hassan S Dashti, Paula-Dene Nesbeth, Brittany Elle Cooper, Yiyi Ma, Yu-Chi Lee, Ruixue Hou, Chao-Qiang Lai, Kris Richardson and José M Ordovás

* Correspondence: laurence.parnell@ars.usda.gov JM-USDA Human Nutrition Research Center on Aging at Tufts University, 711 Washington Street, Boston, MA 02111, USA

\begin{abstract}
Background: Genetic understanding of complex traits has developed immensely over the past decade but remains hampered by incomplete descriptions of contribution to phenotypic variance. Gene-environment (GXE) interactions are one of these contributors and in the guise of diet and physical activity are important modulators of cardiometabolic phenotypes and ensuing diseases.
\end{abstract}

Results: We mined the scientific literature to collect GxE interactions from 386 publications for blood lipids, glycemic traits, obesity anthropometrics, vascular measures, inflammation and metabolic syndrome, and introduce CardioGXE, a gene-environment interaction resource. We then analyzed the genes and SNPs supporting cardiometabolic GxEs in order to demonstrate utility of GxE SNPs and to discern characteristics of these important genetic variants. We were able to draw many observations from our extensive analysis of GxEs. 1) The CardioGxE SNPs showed little overlap with variants identified by main effect GWAS, indicating the importance of environmental interactions with genetic factors on cardiometabolic traits. 2) These GxE SNPs were enriched in adaptation to climatic and geographical features, with implications on energy homeostasis and response to physical activity. 3) Comparison to gene networks responding to plasma cholesterol-lowering or regression of atherosclerotic plaques showed that GXE genes have a greater role in those responses, particularly through high-energy diets and fat intake, than do GWAS-identified genes for the same traits. Other aspects of the CardioGxE dataset were explored.

Conclusions: Overall, we demonstrate that SNPs supporting cardiometabolic GXE interactions often exhibit transcriptional effects or are under positive selection. Still, not all such SNPs can be assigned potential functional or regulatory roles often because data are lacking in specific cell types or from treatments that approximate the environmental factor of the GxE. With research on metabolic related complex disease risk embarking on genome-wide GXE interaction tests, CardioGxE will be a useful resource.

Keywords: Cardiovascular diseases, Diet, Gene-environment interaction, Genetic variants, Phenotypic variance, Physical activity, Type 2 diabetes

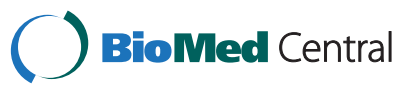

(C) 2014 Parnell et al.; licensee BioMed Central Ltd. This is an Open Access article distributed under the terms of the Creative Commons Attribution License (http://creativecommons.org/licenses/by/4.0), which permits unrestricted use, distribution, and reproduction in any medium, provided the original work is properly credited. The Creative Commons Public Domain Dedication waiver (http://creativecommons.org/publicdomain/zero/1.0/) applies to the data made available in this article, unless otherwise stated. 


\section{Background}

Over the last decade, hundreds of genetic loci have been described as contributors to complex traits and human diseases. Yet, often a large proportion of the heritability of many traits remains ill defined. Contributors to phenotypic variance include: inability of small sample sizes to detect variants with small effects, disease markers not in complete linkage disequilibrium (LD) with the causal variant thus underestimating heritability [1], heritability overestimation from family-based populations, rare or "private" mutations [2,3], inherited patterns of epigenetic marks [4], epistasis (gene-gene interactions) [5,6] and gene-environment (GxE) interactions [7,8]. Of these, the GxE has drawn much attention in part because it describes a modifiable relationship between genetic variation and changes in phenotype, one by which an individual can take action with potential health benefits.

The cell and the organism as a whole are consistently challenged to maintain homeostasis in the face of a wide array of stimuli or perturbations, both health-promoting and diseasecausing. To accomplish homeostasis, adjustments to molecular parameters must be enacted that correspond to the stimulatory challenge, which typically includes altered protein function or gene expression. This all amounts to continual changes to the phenotypes of the cell or organism and it is the timeliness and efficiency of these phenotypic adjustments that determine health and healthy aging. This process can be termed phenotypic flexibility, a phenomenon which is a central concept of the gene-environment interaction [9]. A geneenvironment interaction refers to modification by an environmental factor of the effect of a genetic variant on a phenotypic trait [10]. Environmental factors can include diet, dietary components such as saturated fatty acids, physical activity, sedentary behavior, alcohol, or sleep, among many others. Such GxE interactions can serve to modulate the adverse effects of a risk allele, or can exacerbate the genotype-phenotype relationship and increase risk. Additionally, environmental stimuli, acting over hundreds of generations, can promote adaptation that is observed in current populations as affecting disease risk [11]. Importantly, a complete catalog of GxEs for a given phenotype will provide the means whereby an individual can adjust exposure to a particular environmental factor involved in GxE interactions for the benefit of lessening disease risk according to a fixed genotype.

The genetic basis of transcription rates, particularly as responses to stimuli, and transcription differences between individuals is now widely recognized as commonplace, with important consequences on disease outcomes. Expression quantitative trait loci (eQTL) are currently seen as one important source linking discovery of disease genes to functional mechanisms that are the basis of complex traits [12]. Similarly, loci supporting GxE interactions contribute to variance of complex traits in a manner involving an environmental factor or stimulus and thus likely also represent response eQTL. In addition, genetic variation in cardiometabolic traits results in part from adaption to local environments [13]. Thus, genetic variants that have been subject to positive selection, can interact with environmental factors, such as climate, diet, and lifestyle, leading to increased risk in cardiometabolic diseases [13].

Our 2011 report cataloged 554 GxE interactions, 377 of which contained common traits and environmental factors, that reached statistical significance and were pertinent to nutrition, cardiovascular diseases, blood lipids and type 2 diabetes mined from 184 scientific reports [14]. We inventoried more GxEs for HDL-cholesterol as phenotype and physical activity as modifying environmental factor than any other terms in the 
GxE equation. Overall, obesity anthropometrics was also a leading phenotype with body mass index (BMI) predominating the significant obesity GxEs. As a result of increased GxE reports, the objectives of the current study were to update our 2011 report and show the broad utility of GxE interactions to population genetics and human disease by comparing to other biomedical genomics data.

\section{Methods}

The description of literature mining and building this dataset has been described [14]. Briefly, articles available before September, 2013 were queried at PubMed or www.quertle. info with search terms including genetic variation (e.g., SNP, variant, polymorphism), "interaction," or an environmental factor (e.g., diet, physical activity or exercise, alcohol, sleep, tobacco/cigarette) and, after reading and manual parsing of the data, were incorporated into the update presented here. Specifically, data fields captured included SNPs tested for GxE interactions, the assigned gene for the SNP, common aliases of the SNP, risk allele, phenotype, modifying environmental factor, population ethnicity/origin and PubMed identifier. We excluded all reports on children and adolescents, and any GxE studies examining non-alcoholic fatty liver disease and other phenotypes that are peripherally affiliated with cardiometabolic dysfunction, including atrial fibrillation, cardiomyopathies and response to lipid-lowering, glucose-homeostasis and other medications.

To demonstrate the utility of GxE SNPs within the CardioGxE dataset and interactions they represent, and to offer insight into potential mechanisms of function, we performed a series of comparisons to other biomedical genomics data. These comparisons to test for enrichment included roles in main-effect associations to disease phenotypes, transcriptional control (either via allele-specific expression, microRNA-mRNA interaction or epigenetics), adaptation, and in maintaining metabolic homeostasis in a set of pertinent tissues and cell types. To initiate these analyses, we created two separate SNP datasets based on LD: one for GxE SNPs and another from genome-wide association studies (GWAS) SNPs for the same cardiometabolic traits but not including any SNPs for which there is GxE evidence. Genomic coordinates (dbSNP138) for the region spanning $300 \mathrm{~kb}$ and centered on each SNP were determined. A bash shell script was written to retrieve iteratively all 1000 Genomes Project SNP data (accessed 04/10/2014) within this region from the CEU population using tabix and vcftools [15], pipe these data into Haploview for LD analysis using a $r^{2} \geq 0.80$, and return all variants contained in the LD block of the input SNP [16]. These SNPs were used for further analysis. Significance of enrichment in a comparison between two datasets was performed by two sample $z$-test.

Two measures of positive selection signals for GxE SNPs, integrated haplotype score (iHS) [17] and global Fst, were acquired from data extracted from the 1000 Genome Selection Browser 1.0 [18]. SNPs with $|\mathrm{iHS}| \geq 2.0$ [17], or Fst $\geq 0.5$ [19] were considered as subject to positive selection [17]. For the control, positive selection signals of a matched set of SNPs of significant main effects, but without known GxE interaction, were also obtained from the 1000 Genome Selection Browser 1.0. To determine the enrichment of positive selection variants in $\mathrm{GxE}$ interactions, the $Z$-score test was conducted.

To determine if a GxE SNP or one in LD had evidence of cis or trans eQTL data, we collected significant hits from 5 published eQTL experiments [20-24]. A Perl script was written to search GxE SNPs against each list of significant eQTL hits. 
On the basis of our earlier microRNA (miR) target SNP database [25], we further collected human SNPs that are potentially involved in miR targeting regulation by using miR target prediction algorithms TargetScan [26], TargetScanS, miRanda [27], microRNA.org [28], PITA [29], PicTar [30], mirsnpscore [31] and dbSMR [32]. Targets were downloaded with genome coordinates and mapped to genomic positions according to GRCh37/hg19 using the LiftOver tool from the UCSC Genome Browser and supplemented with any dbSNP137 SNPs located in predicted target sites. SNPs also were collected from published miR SNP databases: PolymiRTS [33], PolymiRTS 2.0 [34], PolymiRTS 3.0 [35], Patrocles [36], PupaSuite 3.1 [37], miRdsnp [38], miRNASNP [39], MirSNP [40] miRcode [41] and other literature resources, including predicted and experimentally validated sites. For SNPs located in miR genes, we used the UCSC Genome Browser tract wgRna_sno/miRNA and limited results to miR precursor forms then by searches for any SNPs positioned within gene regions. For genetic variants affecting miR processing machinery, SNPs were identified that mapped within genes encoding these enzymes.

\section{Results and discussion}

\section{Cardiometabolic GxE interaction catalog}

All GxE interaction tests for cardiometabolic traits from 386 published scientific reports identified by literature mining are presented in Additional file 1. We include tests passing the threshold for statistical significance as reported by the study authors, generally $p<0.05$, plus those tests that are not significant. The CardioGxE catalog is composed of 1187 significant GxEs (in 189 genes) and 13770 with no significant interaction observed. By far, most reports examined populations of European ancestry. Of 1187 significant GxEs, 1013 (85.2\%) involve the typically measured lifestyle choices or environmental factors of physical activity or inactivity, smoking, alcohol consumption and diet. Dietary measures include macronutrient intakes, either as daily amounts or as percent of total energy, of carbohydrates, both simple and complex; protein; and fat, sub-divided into total fat, saturated fatty acid (SFA), mono-unsaturated fatty acid (MUFA), and poly-unsaturated fatty acid (PUFA), with the latter further categorized as N-3 or N-6, omega-3 or omega-6, respectively. Of 1187 significant GxEs, 992 (83.6\%) include the commonly measured phenotypes of blood lipids (HDL-cholesterol, LDLcholesterol, VLDL-cholesterol, total cholesterol, triglyceride), glycemic traits (type 2 diabetes status, plasma glucose and insulin, HOMA-IR, beta cell function as HOMA-BC), obesity anthropometrics (BMI/obesity, adiposity, body weight, waist circumference, waist-to-hip ratio), vascular measures (diastolic and systolic blood pressure), inflammation (C-reactive protein or CRP), and metabolic syndrome, or changes in these values in response to an intervention, typically dietary.

We then trimmed the data to those significant GxEs that contain both common phenotypes and environmental factors producing a list of 654 different significant cardiometabolic GxEs. These GxEs are different in terms of any data parameter including population, or the direction or threshold of the environmental term constituting the GxE interaction. This dataset, although smaller than the 1187 total GxEs mined from the literature, allows for much more direct comparisons to other biomedical and genomics datasets. In our 2011 report, we described 554 different GxE interactions from 184 publications [14]. In that dataset, we cataloged 377 GxEs containing common phenotypes and 
common environmental factors. Thus, while we have observed growth in GxEs for cardiometabolic traits over the past three years, there also have been a few large-scale or genome-wide studies, which have produced a substantial number of interactions not reaching significance, as well as greater diversity in both the phenotypes and environmental terms analyzed.

\section{GXE SNPs involved in genetic-based diseases and GWAS}

The National Human Genome Research Institute (NHGRI) maintains a Clinical Genomic Database [42], a manually curated database of conditions with known genetic causes [43]. These data can be queried to obtain genes implicated in certain medical conditions with regard to the clinical utility of genetic diagnosis. We conducted a query on 22 May 2013 for the term "cardiovascular", which returned 486 different genes, of which 24 have evidence for $\mathrm{GxE}$ interactions for cardiometabolic traits. The corollary of this finding is only 24 of 189 (12.7\%) cardiometabolic GxE genes are present in the clinical genomic dataset, yet these genes are linked to phenotypes pertinent to cardiovascular diseases. Because this observation is general and without regard to specific phenotypes, we sought to look more deeply at the occurrence of genes shared between the CardioGxE catalog and other datasets of gene-phenotype relationships.

GWAS have been powerful interrogators of the genome, identifying genetic sources of phenotypic variance and disease risk. However, the contribution to phenotype variance that could be explained solely by main effect associations for many cardiometabolic traits was quite small [44]. We reasoned that GxE interactions are important contributors to phenotypic variance. Thus, it would be useful to determine the extent to which sets of genes affiliated with certain cardiometabolic traits also show GxE interactions, as well as how often genes supporting GxE interactions for a given trait have no other evidence linking the gene to that trait. We mined four gene and genetic association databases for genes assigned to four different cardiometabolic traits: blood pressure, HOMA-IR, total cholesterol and LDL-cholesterol. These databases were NCBI Gene, the NHGRI GWAS Catalog [45], the PheGenI phenotype-genotype integrator [46], and a recent comprehensive review of coronary artery disease risk factors [47]. That review lists 326 different genes involved in CAD susceptibility or a series of risk factors ranging from blood lipids to glucometabolic traits and C-reactive protein [47]. None of these four databases contained the same number of genes assigned to a given trait, underscoring the fact that all relationships between gene and phenotype are not comprehensively cataloged in one place. For each phenotype, we observed very few genes shared by our GxE catalog with any of the four gene/genetic association data sources, ranging from a minimum of no genes shared to a maximum of $20 \%$ of genes (15 of 75 genes) assigned in the example of LDL-C in NCBI Gene (data not shown).

In order to compare GxE SNPs to SNPs supporting main effect associations, we first compiled a list of SNPs in high LD with the lead GxE SNP. This was done with data from the 1000 Genomes Project in the CEU population with an $r^{2}$ threshold set to 0.80 yielding a set of $3381 \mathrm{GxE}$ SNPs. We then compared these GxE SNPs to SNPs supporting main effect associations to cardiometabolic phenotypes in two important resources. Of 759 SNPs with associations to cardiometabolic phenotypes in the GWAS catalog [45], only $36(4.7 \%)$ show evidence of GxE interactions. In addition, of the 3381 GxE SNPs, 
only 112 (3.3\%), representing 146 unique SNP-phenotype pairs, show an association to a cardiometabolic trait as mined from PheGenI [46]. Furthermore, of these 146 SNPphenotype pairs, only 37 , or $25.3 \%$ support a GxE interaction for the same or very similar phenotype. Taken together, these observations underscore the incomplete description of contribution to phenotypic variance by main effect associations, and strengthen the importance of $\mathrm{GxE}$ interactions as contributors to that variance. This then implies that genetic contributors alone are insufficient diagnostic tools for assessing disease risk, but those calculations also must include at least the GxE term.

\section{Genetics - GxE and epistasis connections}

Epistasis also has been offered as a contributor to the observed variance in disease phenotypes $[5,6]$. Some groups have undertaken a knowledge-driven approach, using shared relationships from protein-protein interaction data or pathway assignment, to identify potential gene-gene or epistatic interactions $[48,49]$. In a similar vein, we hypothesized that epistatic alleles could operate via shared mechanistic linkages and that these could then be observed as coordinate pairs of identical GxE interactions. To test this, we collected epistatic relationships for common cardiometabolic traits from the literature and examined those SNP-phenotype relationships in our GxE catalog.

Of eleven significant gene-gene interaction models discovered in a cohort in which epistasis was examined as a source for phenotypic variance for HDL-C [48], only two epistasis pairs were tested for $\mathrm{GxE}$ interactions for the same HDL-C trait. One, our catalog lists $A B C A 1$ and $L P L$ markers as each having GxE interactions for HDL-C, but always with environmental factors not shared with the other gene. Two, a knowledgedriven screen of GWAS data reported an interaction between LIPC and HMGCR for HDL-C [49], but no GxE interactions for HMGCR are cataloged here. Additional literature mining revealed several gene-gene interactions acting on cardiometabolic traits. We identified just five examples for which the genes containing the epistasis relationship also participate in $\mathrm{GxE}$ interactions for the same phenotype and environmental factor. These include $L E P x L E P R$ on obesity [50] and a change in BMI-low-calorie diet GxE as well as a BMI-PUFA N-6 linoleic acid GxE; ADRB2xADRB3 on BMI [51] and a BMIphysical activity GxE; APOExCETP on HDL-C [52] and GxE interactions for alcohol, fat intake, physical activity or SFA intake; CETPxLIPC on HDL-C [53] and GxE interactions with physical activity, percent energy from animal fat, and intakes of fat, MUFA and SFA; and PPARAxPPARG on small dense LDL [54] and a LDL particle size-SFA intake GxE. Although examination of our GxE catalog shows that the published epistasis gene pairs often are not tested for the same phenotype-environmental factor combination, a number have been tested but few exhibit shared GxE interactions. This may indicate that the pools of genetic factors contributing to phenotypic variance via epistasis and GxE interactions are rather distinct. Comparing to such a small epistasis dataset, however, is insufficient and thus it remains an open question as to how often epistasis genes will share an environmental interaction and reveal any mechanisms of action.

\section{GxE variants under positive selection}

Comparisons of risk allele frequencies across diverse populations have established appreciable directional differentiation for blood lipid and T2DM risk allele frequencies 
$[55,56]$. The decreasing frequencies of some T2DM risk alleles seen along an eastward arc from Africa to eastern Asia supplement disparities in predicted genetic risk, such that a portion of T2DM genetic risk is consistently elevated for individuals in African populations and lower in Asian populations [56], but this is somewhat controversial [57]. Accordingly, and considering that geography and climate strongly influence available foodstuffs, seasonally directed energy expenditures and other nutrition-centric human activity [13], we sought to identify those GxE SNPs that show evidence for positive selection.

Three resources were used to investigate relationships between cardiometabolic GxEs and adaptation to climate and geography. First, two genome-wide studies have examined associations between genetic variants and climatic and geographical characteristics, including latitude, seasonality, precipitation, solar radiation and temperature [58,59]. Second, a collection of genes was identified as under selection in different human populations with roles in cultural practices, often with rationales pertinent to agriculture, diet and societal behaviors [60]. Third, a number of other studies have assessed adaptation at candidate loci for specific phenotypes and we chose to examine those germane to cardiometabolic traits. From these reports, we found that 25 of 189 different genes supporting cardiometabolic GxE interactions show adaptation to climatic and geographical characteristics (Table 1). Just 23 of 453 loci participating in main effect associations for these cardiometabolic traits, as mined from the GWAS catalog [45], show adaptation to climate and geography features, indicating significant enrichment in the GxE dataset ( $p<0.001$, two sample $z$-test).

It is a challenge to understand fully the relationships between factors driving adaptation to a given climate or geographical feature and the phenotype-environment pairings observed in published GxE interactions. Nonetheless, some examples deserve attention. GxE genes ANGPTL4 and PPARA, both expressed in adipocytes, were identified as showing adaptation to high altitude in Tibetans $[62,69]$ and as contributing to variation in HDL-C and other blood lipids (Additional file 1). Interestingly, hypoxia affects preadipocytes and adipocytes in ways that alter lipid droplet size and content, including triglyceride, and protein secretion [70,71]. The $U C P 1$ and $U C P 2$ genes are described as having undergone adaptation to temperature, specifically cold resistance [68], and participate in GxE interactions with energy intake (fuel) on BMI and body weight. Lastly, we note GxE interactions with hormone-sensitive lipase LIPE and physical activity. This gene resides within a region identified as having been subject to a selective sweep in Ethiopian highlanders with respect to hypoxia tolerance adaptation [67]. Overall, we believe that the observed enrichment of GxE genes for adaptation to climate and geographical traits likely originated from energy homeostasis and temperature adaptation as this dictated what food was available, how much energy was expended during daily activities, and what an individual wore (to be warm or cool). Maintaining energy homeostasis and healthy vascular function, which can be promoted by an active lifestyle, are central to diseases such as CVD, T2DM, hypertension, stroke and metabolic syndrome, which are often preceded by abnormal values of the clinical measures constituting this GxE catalog.

Although the work presented here does not explore relationships between genes under selective pressure from pathogen exposure and genes that support cardiometabolic GxE interactions [13], such instances might have relevance to the links between metabolic diseases and inflammation. In this regard, toll-like receptors, including TLR1, have roles in metabolic syndrome in macrophages and other cell types [72], and TLR1 recently was 
Table 1 GxE genes and SNPs under selection for climatic and geographic characteristics

\begin{tabular}{|c|c|}
\hline Gene/SNP & Climate/Geography factor \\
\hline $\begin{array}{l}\text { ACE- } \\
\text { rs7214530 }\end{array}$ & Winter PC1 [58] \\
\hline ADAMTS9 & $\begin{array}{l}\text { Hypoxia - high-altitude Amharans } \\
\text { (Ethiopia) [61] }\end{array}$ \\
\hline$A D H 1 C$ & $\begin{array}{l}\text { Digestion of milk and dairy products; } \\
\text { metabolism of carbohydrates, starch, proteins, } \\
\text { lipids and phosphates; alcohol metabolism [60] }\end{array}$ \\
\hline $\begin{array}{l}\text { ADRA2B- } \\
\text { rs7604842 }\end{array}$ & Summer PC1 [58] \\
\hline ANGPTL4 & Hypoxia - high-altitude Tibetans [62] \\
\hline $\begin{array}{l}\text { APOA4 - } \\
\text { rs5110 }\end{array}$ & $\begin{array}{l}\text { Nutritional advantage to those with } \\
\text { high milk consumption [63] }\end{array}$ \\
\hline CD36 & $\begin{array}{l}\text { Dispersal and subsequent exposure to novel } \\
\text { climates; summer PC1; fat consumption } \\
{[58,60,64]}\end{array}$ \\
\hline CETP & $\begin{array}{l}\text { Dispersal and subsequent exposure to novel } \\
\text { climates; energy metabolism and hot or cold } \\
\text { tolerance; summer PC2 }[58,60]\end{array}$ \\
\hline $\begin{array}{l}\text { CLOCK- } \\
\text { rs1979605 }\end{array}$ & Summer PC2 [58] \\
\hline CYPIA2 & Domestication of plants [60] \\
\hline СYPЗА & $\begin{array}{l}\text { Domestication of plants; aridity (salt retention } \\
\text { adaptation) in some Africans }[60,65]\end{array}$ \\
\hline EDNRA & Hypoxia - high-altitude Tibetans [66] \\
\hline $\begin{array}{l}\text { FABP2- } \\
\text { rs1799883 }\end{array}$ & Latitude [58] \\
\hline
\end{tabular}

Cardiometabolic GxE, phenotypeenvironmental factor

SBP-physical activity; LC

LC

BMI-alcohol consumption; waist circumferencealcohol consumption

T2DM-physical activity; LC

HDL-C-carbohydrate, percent energy from

Varirous GxEs: blood lipids-dietary

fatty acid intake

LC

Cholesterol, total-fat, total intake; $\Delta$ cholesterol, total-SFA, percent energy from; HDL-C-diet (3); HDL-C-physical activity (4); HDL-C-alcohol consumption (2); HDL-C-fat, total, percent energy from; HDL-C-MUFA, percent energy from; HDL-C-SFA, percent energy from; triglyceridealcohol consumption; $L C$

BMI-physical activity; glucose, fasting-MUFA, percent energy from; insulin resistance (HOMA-IR)-MUFA, percent energy from; waist circumference-SFA, percent energy from

myocardial infarction-coffee intake

DBP-sodium intake; SBP-sodium intake; LC

Arterial stiffness-physical activity

$\triangle$ SBP-Mediterranean hypocaloric diet + exercise $(\mathrm{MHD}+\mathrm{E}) ; \Delta$ glucose, fasting $-\mathrm{MHD}+\mathrm{E} ; \Delta \mathrm{LDL}-\mathrm{C}-$ $\mathrm{MHD}+\mathrm{E}$; glucose tolerance-low-fat diet; glucose, fasting-low-fat diet; insulin, plasma, fasting-lowfat diet; $L C$

(see above)

Dispersal and subsequent exposure

GNPDA2 Precipitation; summer [59]

LEPR-

Winter PC1 [58]

rs1137100

LEPR Digestion of milk and dairy products; metabolism of carbohydrates, starch, proteins, lipids and phosphates; alcohol metabolism; energy metabolism, hot or cold tolerance; latitude, summer PC2; winter PC1 [58,60]

Dairy farming and milk usage; dietary preferences; alcohol consumption [60]

Hypoxia - high-altitude Ethiopians [67] climates; winter PC2 [58,60]
$\Delta$ body weight-weight-loss intervention + exercise

SBP-physical activity; $\Delta$ insulin, fasting-physical activity (HOMA-IR)-PUFA, N-3, plasma; insulin resistance (HOMA-IR)-PUFA, N-6, plasma; insulin, plasma, fasting-PUFA, N-3, plasma; insulin, plasma, fasting-PUFA, N-6, plasma; $\triangle \mathrm{SBP}-\mathrm{MHD}+\mathrm{E}_{i}$ $\triangle \mathrm{BMI}-\mathrm{MHD}+\mathrm{E} ; \Delta$ body weight-MHD $+\mathrm{E}_{;}$ $\Delta$ waist circumference-MHD $+E_{;} L C$

BMI-lactose; body weight-lactose; waist circumference-lactose

BMI-physical activity; cholesterol:HDL-C ratio-physical activity; LC

Lp (a), plasma-fish intake

Cholesterol, total-smoking; HDL-C-physical activity; HDL-C-PUFA, N-9, oleic acid intake; LDL-C-smoking; triglyceride-smoking; LC
$\Delta$ body weight-low-calorie diet; insulin resistance 
Table 1 GxE genes and SNPs under selection for climatic and geographic characteristics (Continued)

\begin{tabular}{|c|c|c|}
\hline PON1 & $\begin{array}{l}\text { Dispersal and subsequent exposure to novel } \\
\text { climates; summer PC } 1[58,60]\end{array}$ & (see above) \\
\hline PPARA & Hypoxia - high-altitude Tibetans [62] & $\begin{array}{l}\text { CRP, plasma-PUFA, N-3, percent energy from; } \\
\text { triglyceride-PUFA, N-3, percent energy from; } \\
\text { triglyceride-PUFA, N-6, percent energy from; } \\
\text { triglyceride-PUFA, percent energy from; waist } \\
\text { circumference-fat, total intake; waist } \\
\text { circumference-SFA intake; HDL-C-PUFA intake; LC }\end{array}$ \\
\hline PPARD & $\begin{array}{l}\text { Dairy farming and milk usage; dietary } \\
\text { preferences; alcohol consumption [60] }\end{array}$ & $\begin{array}{l}\Delta H D L-C \text {-physical activity; } L D L \text { particle size-PUFA: } \\
\text { SFA ratio; } \Delta \text { VO2max-physical activity; } \Delta \text { work } \\
\text { output, max-physical activity; } L C\end{array}$ \\
\hline $\begin{array}{l}\text { PPARGC1A- } \\
\text { rs4550905 }\end{array}$ & Winter PC1 [58] & $\begin{array}{l}\text { BMI-alcohol consumption; BMI-physical activity; } \\
\text { Ainsulin resistance (HOMA-IR)-low-calorie diet; LC }\end{array}$ \\
\hline $\begin{array}{l}\text { TCF7L2- } \\
\text { rs11196175 }\end{array}$ & Summer PC1 [58] & $\begin{array}{l}\text { Glucose, fasting-fat, total, percent energy from; } \\
\text { insulin resistance (HOMA-IR)-fat, total, percent } \\
\text { energy from; insulin sensitivity-SFA, percent } \\
\text { energy from; insulin, plasma, fasting-SFA, percent } \\
\text { energy from; metabolic syndrome-SFA, percent } \\
\text { energy from; LC }\end{array}$ \\
\hline $\begin{array}{l}\text { UCP1- } \\
\text { rs1800592 }\end{array}$ & Temperature - cold resistance [68] & $\begin{array}{l}\Delta B M l \text {-energy intake; } \Delta \text { body weight-energy } \\
\text { intake; } \Delta \text { waist circumference-energy intake; } L C\end{array}$ \\
\hline $\begin{array}{l}\text { UCP2- } \\
\text { rs659366 }\end{array}$ & Temperature - cold resistance [68] & $\begin{array}{l}\Delta \text { body weight-high-calorie diet; } \triangle \mathrm{BMI-low-} \\
\text { calorie diet; BMl-homestead; } L C\end{array}$ \\
\hline $\begin{array}{l}\text { UCP3- } \\
\text { rs1800849 }\end{array}$ & Temperature - cold resistance [68] & BMI-physical activity \\
\hline UCP3 & $\begin{array}{l}\text { Dispersal and subsequent exposure to novel } \\
\text { climates; winter } \mathrm{PC} \text {; } \text {; temperature - cold } \\
\text { resistance }[58,60]\end{array}$ & $\Delta$ body weight-high-calorie diet \\
\hline
\end{tabular}

When no SNP is listed, only the gene itself was shown to be under selection.

bold = phenotype-environment pair found in (n) studies.

$L C=$ selected GxEs based less common phenotypes or environmental factors can be found in (Additional file 1)

$\Delta$ refers to a change in the phenotype, typically after an intervention.

described as having been under selective pressure in Roma gypsy and European populations in response to Yersinia pestis, the agent of plague [73]. TLR4 variants support GxE interactions with obesity traits and smoking in an Argentinean population of European ancestry [74]. Identification of other immuno-metabolic genes that support cardiometabolic GxEs is intriguing but has not been explored sufficiently.

In other work, we examined our catalog of GxE variants and the GWAS-based main effect SNPs for signals of recent positive selection in populations of European ancestry with data from the 1000 Genome Selection Browser [18]. As noted in Table 2, there is no significant enrichment of positive selection based on Fst or iHS values when comparing a set of LD blocks derived from GxE interactions for cardiometabolic traits to a set of GWAS-detected LD blocks that support main effect, but non-GxE associations for the same traits. This could be interpreted in any of several ways. First, the environment indeed has exerted selective pressure on certain variants affecting cardiometabolic

Table 2 Frequency of cardiometabolic GxE and GWAS SNPs under positive selection

\begin{tabular}{|c|c|c|c|c|c|c|c|}
\hline Dataset, all cardiometabolic traits & \# LD blocks & $\begin{array}{c}\text { \# with Fst or } \\
\text { iHS (\%) }\end{array}$ & $p$ & $\begin{array}{l}\text { \# with } \\
\text { Fst (\%) }\end{array}$ & $p$ & $\begin{array}{l}\text { \# with } \\
\text { iHS (\%) }\end{array}$ & $P$ \\
\hline nonGxE GWAS & 549 & $88(16.0)$ & 0.61 & $21(3.8)$ & 0.66 & $70(12.8)$ & 0.44 \\
\hline GXE & 178 & 30 (16.9) & & $8(4.5)$ & & $22(12.4)$ & \\
\hline
\end{tabular}

$p$-value based on two-sample $z$-test. 
traits and disease risk, but the main effect GWAS associations also support as yet undescribed GxE interactions. Two, some effects of the environment are spread across the Homo sapiens species and are not detected as specific to populations of a single ancestry and thus may be observed as main effect associations. Three, the environmental factors driving selection at the GxE or GWAS loci could be quite different, but although these factors remain unknown, interpretation of this result is hindered. In addition, we observed no significant enrichment for Fst or iHS signals in LD blocks supporting HDL-C or physical activity GxEs compared to all cardiometabolic GxEs (data not shown). However, because a genetic marker that associates with HDL-C levels, or any other trait, may either support an as yet untested GxE interaction or a GxE for another, even unrelated phenotype, any enrichment of HDL-C GxE loci under selection compared to main effect loci cannot be fully known.

Seeking to add further support to the hypothesis that many environment-sensitive genes and their variants that function in human disease have been or are under selective adaptation, a theme we have explored with respect to heart disease risk [11], we examined the pathway whose genes proportionately have the greatest level of Neanderthal admixture with subsequent recent positive selection preferentially in contemporary Europeans to retain those sequences [75]. This pathway is involved in lipid catabolism and many of its 38 genes show expression divergence in brain of contemporary humans of European but not East Asian or African descent [75]. Seven of these lipid catabolism genes have been tested for GxE interactions in numerous populations: ANGPTL3, APOA4, APOA5, CPT1A, CPT1B, PPARA and PPARD. In non-European populations 252 different GxE tests with any of these seven genes have been performed and 33 (13.1\%) were significant; in populations with European ancestry 437 such tests were performed giving 95 (21.7\%) significant $\mathrm{GxE}$ interactions. This difference between ancestries is significant $(p=0.002$, two-sample $z$-test) with certain implications for cardiometabolic disease risk. Furthermore, this may lend support to adaptation by Europeans to geographical specificities of that continent, but does not dismiss the possibility of complex population structure in Africa at the time of divergence of the human and Neanderthal lineages [75].

\section{Pathway analysis - GxE genes and cellular function}

Regarding physiological and biological pathways, the phenotypes forming the GxE interactions cataloged here are generally well understood. Also, within many GxE genes there are interactions involving the same phenotype but with different environmental factors or involving the same environmental factor acting upon several phenotypes. Lastly, pathway analysis based on environmental factors, in our opinion, will be more robust once GxE GWIS results are collected and the involved variants are fully characterized. For these reasons, we opted not to perform a traditional test of pathway or gene ontology enrichment for sets of GxE genes, for example for all GxEs affecting triglycerides (TG) or all GxEs pertaining to SFA intake or even all TG-SFA GxEs, but to examine the GxE gene function in the context of metabolic syndrome (MetS). To accomplish this, we mined from a series of 12 electronic posters depicting MetS in six organs or tissues and six cell types [72] whether a gene with variants supporting a cardiometabolic GxE interaction or its encoded protein was present. We considered the presence of a gene or protein as indicative of a key function in the development or 
progression of MetS. Across all six cell types of adipocyte, hepatocyte, islet cell, macrophage, myocyte and neuron, we noted with interest that many GxE proteins function in a MetS context at or very near the cell surface (i.e., in the plasma membrane (PM) or physical interaction with a PM-associated protein). This is a logical site for a protein whose gene is part of an allele-specific response to an environmental stimulus, which arrives in some form at the cell surface. Similarly, it has been observed that GxE genes are enriched in cell communication and cell surface activities [76].

Second, a comparison to pathways relevant to metabolic syndrome and metabolic homeostasis [72] showed that the tissues or cell types that have the greatest frequency of genes that support GxE interactions are the adipocyte and the myocyte. From 22\% to $25 \%$ of all genes depicted as pathway entities under either metabolic homeostasis or metabolic syndrome for these two cell types have evidence in the literature as participating in GxE interactions for cardiometabolic phenotypes. Other organs or cell types, such as brain (13-16\%), neuron (14\%), islet cell (12\%), macrophage (16\%) and hepatocyte (18\%), have lower occurrences, a result which may arise from the high number of GxEs with physical activity. In support of these findings, a recent report on an environmentwide association study (EWAS) in the National Health and Nutrition Examination Survey (NHANES) showed that low physical activity is one of the main environmental factors contributing to all-cause mortality [77], and physical activity often lowers risk in GxE interactions. Thus, it might be more fruitful to direct efforts at identifying novel cardiometabolic GxE interactions to pathways that are functional in the adipocyte and myocyte. The other main factors contributing to all-cause mortality in the NHANES EWAS - lycopene intake, smoking status/exposure and cadmium levels - are not routinely analyzed as components of GxE interactions or high-confidence measures of intakes do not exist. When such measures are reported, genetic variation has been measured sparsely or the data are too difficult to acquire, thereby preventing thorough GxE analysis.

\section{GXE allele-specific effects on transcription: eQTL}

We reasoned that SNPs forming GxE interactions for phenotypes that are highly relevant to a particular tissue will more frequently support allele-specific gene expression in that tissue, with a rationale similar to that showing SNPs associated with type 2 diabetes and related traits are enriched in islet cell-specific enhancers [78]. Thus, as our primary interest is in blood lipids, we examined GxEs for these traits and their relationship with expression quantitative trait loci (eQTL) in liver, as this tissue is highly relevant to these phenotypes. Of 27 triglyceride GxE SNPs, two showed eQTL in liver: rs934197 (LD with rs7575840 mapping to $A P O B$ ) and rs1800588 (LD with rs1077834 mapping to LIPC). This is about a 4.9-fold ( $p<0.01$, two-sample z-test) enrichment over triglyceride GxE SNPs supporting eQTL not in liver. Similarly, we found a significant enrichment of HDL-C GxE SNPs supporting liver eQTL $(p<0.01$ ), including rs34367192 (LD with rs10495562 mapping to ADAM17), rs6720173 (LD with rs3792009 mapping to ABCG5), and rs1800588 and rs2070895 (both in LD with rs1077834 mapping to LIPC). Lastly, for LDL-C traits, we observed a significant enrichment of LDL-C GxE SNPs supporting liver eQTL $(p<0.01)$, including rs34367192 (LD with rs10495562 mapping to ADAM17), rs1800591 (LD with rs11937107 mapping to MTTP), and rs2070895 (LD with rs1077834 mapping to LIPC). All liver eQTL SNPs discussed here associate with mRNAs for the gene to which the SNP 
maps, except for rs7575840 associating with a transcript just upstream of $A P O B$. No GxE SNPs for total cholesterol support eQTL in liver. Although the reported incidences of liverbased $\mathrm{eQTL}$ are small and dictate caution regarding interpretation, the consistency of the above enrichments is intriguing and suggested a comparison between GxE and GWAS signals for tissue-specific eQTL.

In order to assess the impact of the eQTL in main effects compared to environmental interactions, we tested whether CardioGxE-based LD blocks for a given trait are more likely to share a liver eQTL than GWAS-based markers. We examined LD blocks from both GxE and GWAS sources for all cardiometabolic traits and each of four main blood lipids for overlap with liver eQTL. Specifically, a comparison of GxE LD blocks and those GWAS LD blocks not overlapping with the GxE set showed no significant enrichment in liver eQTL associations, with one exception (Table 3). Notably, only one GxE LD block for total cholesterol contains a liver eQTL association and this low number gives an unreliable $p$-value of enrichment in the GWAS samples. Nonetheless, these results overall may be indicative of main effect SNPs exerting function in a tissue or cell type principal to that phenotype and the GxE SNP could be sensing differentials in environmental factors in other or peripheral tissues. Alternatively, the observation of no enrichment could indicate that there are equal effects on transcription across sources of trait variation, but these may operate in different tissues with respect to GxE and main effect. For example, brain and gut eQTL are not readily available for such analyses and GxEs may function in those organs with influences on hunger, satiety, lipid catabolism, cholesterol synthesis, or nutrient absorption. Lastly and perhaps most importantly, eQTL data are lacking for the response to a challenge that closely mimics the environmental factor in the GxE equation.

\section{GxE allele-specific effects on transcription: microRNAs}

Human microRNAs (miRs) have emerged as important epigenetic regulators of cardiometabolic traits $[79,80]$. Genetic variants involved in miR-mediated regulation have been shown to affect gene expression [81-83] and thus are suggested to contribute to phenotypic variation. As the environment can modulate miR levels, we hypothesized that GxE SNPs can function through miR-mediated regulation. In order to focus efforts

Table 3 Lack of enrichment for liver eQTL in GxE SNPs compared to GWAS SNPs

\begin{tabular}{|c|c|c|c|}
\hline Dataset & LD blocks: type, $n$ & LD blocks with liver eQTL (\%) & $p$ \\
\hline \multirow[t]{2}{*}{ All cardiometabolic traits } & nonGxE GWAS, 549 & $35(6.4)$ & 0.26 \\
\hline & GxE, 178 & $9(5.1)$ & \\
\hline \multirow[t]{2}{*}{$\mathrm{HDL}-\mathrm{C}$} & nonGxE GWAS, 69 & $8(11.6)$ & 0.21 \\
\hline & GxE, 43 & $3(7.0)$ & \\
\hline \multirow[t]{2}{*}{ LDL-C } & nonGxE GWAS, 54 & $6(11.1)$ & 0.32 \\
\hline & GxE, 37 & $3(8.1)$ & \\
\hline \multirow[t]{2}{*}{ Triglyceride } & nonGxE GWAS, 45 & 7 (15.6) & 0.08 \\
\hline & GxE, 35 & $2(5.7)$ & \\
\hline \multirow[t]{2}{*}{ Total cholesterol } & nonGxE GWAS, 55 & $10(18.2)$ & 0.02 \\
\hline & GxE, 33 & $1(3.0)$ & \\
\hline
\end{tabular}


on human SNPs likely to participate in miR targeting, we created a genome-wide miR regulatory SNP database ( $900,000 \mathrm{SNPs})$ by integrating miR targeting prediction algorithms and databases from various resources. This comprehensive database allows assessment of the genetic effect of miR-mediated regulation on traits of interest. We searched GxE SNPs and their proxies against our miR SNP database to identify potential allele-specific miR-mRNA interactions and any miR-phenotype or miR-environmental factor relationships.

A miR SNP confidence score was created by counting for each SNP the number of supported algorithms, datasets or tables supporting a genetic effect of miR-mediated regulation in order to rank the likelihood that a SNP is a miR regulatory SNP. Confidence scores for the GxE miR SNPs and their proxies ranged from $0-13$. We collected all potential (predicted and experimentally validated) regulatory miRs for each SNP with a miRSNP confidence score $>3$ (13 lead and 46 proxy SNPs) and identified the most frequently participating miRs among GxE miR SNPs (Table 4). Such commonly occurring miRs could serve as agents of a given phenotype or environmental factor preferentially. However, no easily discernible trends were noted, suggesting that miRmediated regulation by GxE SNPs is highly specific or networked with other miRs. More research is needed to evaluate this. Our finding may be explained by the general understanding in the field that miR regulation is tissue specific and fine tunes gene expression in a precise physiological or metabolic response. Furthermore, as few common miRs have been assigned roles in GxE interactions or even in specific cellular challenges that imitate the environmental component of these GxEs, mechanistic interpretation of the participating alleles is difficult.

\section{GxE allele-specific effects on transcription: epigenetics}

As DNA methylation is a well known marker for environmental change, we thought it of interest to examine whether the GxE SNPs are related to potential DNA methylation. From 180 SNPs that support GxE interactions and have unique coordinates in the dbSNP135 database, 79 (44\%) either create or destroy a CpG dinucleotide, double the percent across all dbSNP135 data (22\%). In addition, we find that 16 of these 79 variants map to within $3 \mathrm{~kb}$ of a CpG island, as downloaded from the UCSC genome browser. These results identify an accumulation of such CpG-altering SNPs (CGS), a type of SNP with particular relationships to DNA methylation [84,85], in cardiometabolic GxE interactions and suggest that these SNPs can exert impact on gene regulation in response to environmental factors and exposure over time. In this context, 5 of 16 CGSs within $3 \mathrm{~kb}$ of a CpG island also exhibit eQTL associations: rs659366, rs5128 (via LD to rs10047462), rs876493, rs8065443 and rs1568400. Hence, epigenetic differences that alter gene activity could underlie some inter-individual differences in obesity and other cardiometabolic phenotypes, and that relationship could be modified by both genetic and environmental factors [86]. On the other hand, of 102 human genes showing differential DNA methylation at CpG sites and differential mRNA expression of the nearest gene in pancreatic islets in a comparison of nondiabetics and T2DM subjects [87], only ACSL5, IRS1 and SLC44A4 are known to support cardiometabolic GxE interactions. That only IRS1 participates in GxEs with glycemic phenotypes suggests a lack of evidence supporting strong connections between genetic variation, GxE interactions and epigenetics. Clearly, this analysis can be conducted more thoroughly once epigenetic and eQTL datasets expand to other tissues and cellular challenges. 
Table 4 Potential regulatory miRNAs involved in allele-specific miR-mRNA interactions showing GxE interactions

\begin{tabular}{|c|c|c|c|c|c|}
\hline SNP & Lead SNP & Gene & miRSNP confidence score & Potential regulatory miRNAs* & Cardiometabolic GxE, phenotype-environmental factor \\
\hline rs1063539 & rs1063539 & ADIPOQ & 5 & miR-593-3p & $\begin{array}{l}\text { Obesity-PUFA, N-3, DHA + EPA, percent in erythrocyte } \\
\text { membranes }\end{array}$ \\
\hline rs12817689 & rs2302706 & $M M A B$ & 7 & $\begin{array}{l}\text { miR-33b-3p, miR-371a-3p, miR-371b-3p, } \\
\text { miR-515-3p, miR-519e-3p }\end{array}$ & HDL-C-carbohydrate intake \\
\hline rs1491235 & rs1800591 & MTTP-TRMTIOA & 5 & miR-33b-5p & $\begin{array}{l}\text { APOB-48 in VLDL-high-fat challenge; cholestanol/mol } \\
\text { cholesterol, serum, fasting-diet; cholesterol in VLDL-high- } \\
\text { fat challenge; } \Delta \text { LDL-C-SFA, percent energy from; } \\
\text { lathosterol/mol cholesterol, serum, fasting-diet; sitosterol/ } \\
\text { mol cholesterol, serum, fasting-diet }\end{array}$ \\
\hline rs3734254 & rs2076167 & PPARD & 11 & miR-885-3p & $\begin{array}{l}\Delta H D L-C-\text { physical activity; } \Delta \text { work output, max-physical } \\
\text { activity }\end{array}$ \\
\hline rs4225 & rs5070 & APOC3 & 6 & miR-885-3p & HDL-C-fat, total intake; HDL-C-SFA intake \\
\hline rs4707436 & rs1049353 & CNR1 & 12 & miR-593-5p, miR-885-5p & $\begin{array}{l}\Delta \text { cholesterol, total-MUFA, percent energy from; } \Delta \text { cholesterol, } \\
\text { total-PUFA, percent energy from; } \Delta L 6 \text {, plasma-physical } \\
\text { activity during energy restriction; } \Delta L D L-C-M U F A \text {, percent } \\
\text { energy from; } \Delta L D L-C-P U F A \text {, percent energy from; } \Delta \text { leptin, } \\
\text { plasma-physical activity during energy restriction; } \Delta \text { resistin, } \\
\text { plasma-physical activity during energy restriction; } \Delta T N F \text {, } \\
\text { plasma-physical activity during energy restriction }\end{array}$ \\
\hline rs4998 & rs4994 & ADRB3 & 6 & miR-593-5p, miR-885-3p & $\begin{array}{l}\text { BMI-energy intake; } \Delta \text { fat mass-physical activity; } \Delta \text { lean } \\
\text { mass-physical activity; obesity-physical activity; triglyceride- } \\
\text { low-calorie diet }\end{array}$ \\
\hline rs5446 & rs5443 & GNB3 & 10 & $\begin{array}{l}\text { miR-33b-3p, miR-371a-3p, miR-371b-3p, } \\
\text { miR-515-3p, miR-519e-3p }\end{array}$ & BMI-physical activity \\
\hline rs7021 & rs709592 & PSMD3 & 9 & $\begin{array}{l}\text { miR-33b-3p, miR-371a-3p, miR-515-3p, } \\
\text { miR-519e-3p }\end{array}$ & $\begin{array}{l}\text { Glucose, fasting-carbohydrate, percent energy from; } \\
\text { glucose, fasting-MUFA, percent energy from; insulin } \\
\text { resistance (HOMA-IR)-carbohydrate, percent energy from }\end{array}$ \\
\hline
\end{tabular}

text should read as follows: Across all miRSNP data, the maximum confidence score was 24 , and for this analysis that range was 0-13, with a higher score indicating higher confidence in the miR regulatory function. *All miRs listed contain the prefix hsa-. 
GxE allele-specific effects on transcription: gene networks and atherosclerosis

Many phenotypes discussed in the context of GxE interactions are valued by health professionals as indicators or clinical measures of risk and severity of diseases, such as stroke, myocardial infarction and type 2 diabetes. Ideally, when such a clinical indicator exceeds some threshold, a first treatment option is an adjustment to lifestyle, mainly a healthier diet and increased exercise. A recently published study identified genes expressed in mouse aorta that form the basis of the response to regression of atherosclerotic plaques independent of a different set of genes simply responding to a lowering of plasma cholesterol [88]. Although both the plasma cholesterol-lowering and plaque regression gene networks contain genes identified in GWAS for the cardiometabolic traits presented in our GxE catalog, there is a significantly higher prevalence of GxE genes over GWAS genes in these two expression networks. Of 519 GWAS genes for these traits, 80 and 174 are observed in the plasma cholesterol-lowering and plaque regression gene sets, respectively, but of $108 \mathrm{GxE}$ genes associating with often measured phenotypes and environmental factors, 32 and 55 are observed in the same cholesterol-lowering and plaque regression gene sets, respectively. In both comparisons of GxE to GWAS genes, enrichment in the gene sets is significant with $p<0.001$ (Table 5). Thus, the overlap of genes responding either to plaque regression or reduction in plasma cholesterol, with genes participating in GxE interactions, of which most contain an environmental term entailing physical activity, energy from fat or total energy, is significantly more than for GWAS. This is reasonable and offers the opportunity to focus efforts to identify the genetic basis of differential responses to cholesterol-lowering dietary interventions.

\section{Conclusions}

While it certainly may be stated that a person's 'genometype' could indeed prove the most useful for individualized medicine (including individualized nutrition) and personal genetics [89], the impact of environmental interactions on a person's panel of alleles cannot be overstated. In this regard, an interaction between an obesity genetic risk score based on 63 variants and saturated fat intake has been demonstrated in two distinct populations [90]. We have not in this analysis coalesced the genetic variants cataloged in CardioGxE around a given phenotype-environmental factor pair and processed data for a global or genometype GxE interaction, but such research could proceed with the aid of this GxE resource. Indeed, the lack of overlap between our CardioGxE dataset and published GWAS for comparable phenotypes makes evident the utility of incorporating GxEs into assessment of disease risk in two important ways. One, a GxE catalog provides the means to develop a better strategy of intervention

Table 5 Plasma cholesterol-induced lesion networks are enriched for cardiometabolic GxE genes

\begin{tabular}{lccc}
\hline $\begin{array}{l}\text { Network, number } \\
\text { of genes* }^{*}\end{array}$ & $\begin{array}{c}\text { Genes shared with } \\
\text { GxE catalog }\end{array}$ & $\begin{array}{c}\text { Genes shared with } \\
\text { GWAS catalog }^{\ddagger}\end{array}$ & $\begin{array}{c}\text { Enrichment in GxE } \\
\text { catalog, } \boldsymbol{p} \text {-value }^{+}\end{array}$ \\
\hline Plasma cholesterol-lowering, 2697 & 32 & 80 & $<0.001$ \\
Regression-reactive, 6096 & 55 & 174 & $<0.001$ \\
\hline
\end{tabular}

*All genes comprising each network, as described [88].

${ }^{\dagger}$ GxE genes supporting commonly measured phenotypes and involving common environmental modifiers, $\mathrm{n}=108$.

${ }^{\ddagger}$ GWAS genes supporting associations with cardiometabolic phenotypes, $\mathrm{n}=519$.

$p$-value based on two-sample $z$-test. 
because genetic and environmental factors combined can equip the physician for more accurate prediction of future disease risk and hence disease prevention. Two, genetic variation alone is not just diagnostic of disease risk, but is a component of and should be considered in epistatic and $\mathrm{GxE}$ interactions to better inform the individual of potential disease risk. Altogether, the numerous examples presented here add to the emerging view that GxEs are widespread and significant contributors to phenotypic variance [91]. Although we have highlighted instances for which more data are needed, especially taken under conditions mimicking the environmental factor of the GxE equation, the insight thus far garnered from analysis of a large GxE catalog emphasizes the influential roles of environmental factors in the genetics of complex traits, particularly those of a metabolic nature.

\title{
Additional file
}

Additional file 1: The CardioGxE catalog of gene-environment interactions for cardiometabolic phenotypes.

\begin{abstract}
Abbreviations
BMI: Body mass index; CAD: Coronary artery disease; CEU: Utah residents with ancestry from northern and western Europe, from the Centre d'Etude du Polymorphisme Humain collection; CGS: CpG-altering SNP; CVD: Cardiovascular disease; DBP: Diastolic blood pressure; eQTL: Expression quantitative trait locus; EWAS: Environment-wide association study; Fst: Fixation statistics; GWAS: Genome-wide association study; GWIS: Genome-wide interaction study; GxE: Gene by environment (interaction); HDL: High-density lipoprotein; HDL-C: High-density lipoprotein cholesterol; HOMAIR: Homeostasis model assessment-estimated insulin resistance; iHS: Integrated haplotype score; LD: Linkage disequilibrium; LDL: Low-density lipoprotein; LDL-C: Low-density lipoprotein cholesterol; MetS: Metabolic syndrome; miR: microRNA; MUFA: Mono-unsaturated fatty acid; NHANES: National Health and Nutrition Examination Survey; PUFA: Poly-unsaturated fatty acid; SBP: Systolic blood pressure; SFA: Saturated fatty acid; SNP: Single nucleotide polymorphism; T2DM: Type 2 diabetes mellitus; TG: Triglyceride; VLDL: Very low-density lipoprotein.
\end{abstract}

\section{Competing interests}

The authors declare that they have no competing interests.

\section{Authors' contributions}

LDP conceived of the study, managed the project, performed all analyses not specifically mentioned here, and wrote the manuscript. LDP and BAB mined the literature and populated the updated database. KR acquired the LD SNPS, and mined eQTL data, and LDP analyzed and interpreted those results. BEC and HSD compared GxE SNPS to GWAS databases. RH mined for cardiometabolic GxE-epistasis overlap. PDN identified GxE variants and genes under selection from climatic and geographical features. CQL identified GXE variants showing adaptation by Fst and iHS. MetS pathway analysis was undertaken by BAB. Identification of the GXE SNP effects on miR-mRNA interactions was performed by YCL. Analysis of GXE SNPS affecting potential CPG islands was done by YM. LDP and JMO have given final approval of the published version of this report, and provided financial support. All authors aided in interpretation of results, and read and revised the manuscript.

\section{Acknowledgements}

This work is supported in part by National Institutes of Health (5R21HL114238-02) to LDP. This material is based upon work supported by the U.S. Department of Agriculture, under agreement No. 58-1950-0-014. Any opinions, findings, conclusion, or recommendations expressed in this publication are those of the authors and do not necessarily reflect the view of the U.S. Department of Agriculture.

The attached data and format of Additional file 1 are provided "as is", without warranty of any kind, express or implied including but not limited to the warranties of merchantability, fitness for a particular purpose, non-infringement, and any warranty that these data and format are free from defects. In no event shall USDA be liable for any claim, loss, damages or other liability, whether in an action of contract, tort or otherwise, arising from, out of or in connection with the data and format or the use or other dealings in the data and format. The data and format only have been reviewed and tested under the specific conditions described in this article. USDA does not support and has no connection to any results obtained by using the data and format outside of the specific conditions described in this article.

Mention of trade names or commercial products in this publication is solely for the purpose of providing specific information and does not imply recommendation or endorsement by the U.S. Department of Agriculture. The USDA is an equal opportunity provider and employer. The authors wish to express gratitude to Caren E Smith for critical review of the manuscript. 
References

1. Lai C, Lyman RF, Long AD, Langley CH, Mackay TF: Naturally occurring variation in bristle number and DNA polymorphisms at the scabrous locus of Drosophila melanogaster. Science 1994, 266:1697-1702.

2. Tachmazidou I, Dedoussis G, Southam L, Farmaki AE, Ritchie GR, Xifara DK, Matchan A, Hatzikotoulas K, Rayner NW, Chen Y, Pollin TI, O'Connell JR, Yerges-Armstrong LM, Kiagiadaki C, Panoutsopoulou K, Schwartzentruber J, Moutsianas L, UK10K consortium, Tsafantakis E, Tyler-Smith C, McVean G, Xue Y, Zeggini E: A rare functional cardioprotective APOC3 variant has risen in frequency in distinct population isolates. Nat Commun 2013, 4:2872

3. Lange LA, Hu Y, Zhang H, Xue C, Schmidt EM, Tang ZZ, Bizon C, Lange EM, Smith JD, Turner EH, Jun G, Kang HM, Peloso G, Auer P, Li KP, Flannick J, Zhang J, Fuchsberger C, Gaulton K, Lindgren C, Locke A, Manning A, Sim X, Rivas MA, Holmen OL, Gottesman O, Lu Y, Ruderfer D, Stahl EA, Duan Q, et al: Whole-exome sequencing identifies rare and low-frequency coding variants associated with LDL cholesterol. Am J Hum Genet 2014, 94:233-245.

4. Nelson VR, Spiezio SH, Nadeau JH: Transgenerational genetic effects of the paternal Y chromosome on daughters' phenotypes. Epigenomics 2010, 2:513-521.

5. Haig D: Does heritability hide in epistasis between linked SNPs? Eur J Hum Genet 2011, 19:123.

6. Lanktree MB, Hegele RA: Gene-gene and gene-environment interactions: new insights into the prevention, detection and management of coronary artery disease. Genome Med 2009, 1:28.

7. Andreassi MG: Metabolic syndrome, diabetes and atherosclerosis: influence of gene-environment interaction. Mutat Res 2009, 667:35-43.

8. Zheng JS, Arnett DK, Lee YC, Shen J, Parnell LD, Smith CE, Richardson K, Li D, Borecki IB, Ordovás JM, Lai CQ: Genome-wide contribution of genotype by environment interaction to variation of diabetes-related traits. PLoS One 2013, 8:e77442.

9. van Ommen B, van der Greef J, Ordovas JM, Daniel H: Phenotypic flexibility as key factor in the human nutrition and health relationship. Genes Nutr 2014, 9:423.

10. Ordovas JM: Genotype-phenotype associations: modulation by diet and obesity. Obesity 2008, Suppl 3:S40-S46.

11. Parnell LD, Lee YC, Lai CQ: Adaptive genetic variation and heart disease risk. Curr Opin Lipidol 2010, 21:116-122.

12. Stranger BE, Raj T: Genetics of human gene expression. Curr Opin Genet Dev 2013, 23:627-634.

13. Lai CQ: Adaptive genetic variation and population differences. Prog Mol Biol Trans/ Sci 2012, 108:461-489.

14. Lee YC, Lai CQ, Ordovas JM, Parnell LD: A database of gene-environment interactions pertaining to blood lipid traits, cardiovascular disease and type 2 diabetes. J Data Mining Genomics Proteomics 2011, 2:106.

15. Danecek P, Auton A, Abecasis G, Albers CA, Banks E, DePristo MA, Handsaker RE, Lunter G, Marth GT, Sherry ST, McVean G, Durbin R, 1000 Genomes Project Analysis Group: The variant call format and VCFtools. Bioinformatics 2011, 27:2156-2158.

16. Barrett JC, Fry B, Maller J, Daly MJ: Haploview: analysis and visualization of LD and haplotype maps. Bioinformatics 2005, 21:263-265.

17. Voight $B F$, Kudaravalli $S$, Wen $X$, Pritchard JK: A map of recent positive selection in the human genome. PLOS Biol 2006, 4:e72.

18. Pybus M, Dall'Olio GM, Luisi P, Uzkudun M, Carreño-Torres A, Pavlidis P, Laayouni H, Bertranpetit J, Engelken J: 1000 Genomes Selection Browser 1.0: a genome browser dedicated to signatures of natural selection in modern humans. Nucleic Acids Res 2014, 42:D903-D909.

19. Myles S, Tang K, Somel M, Green RE, Kelso J, Stoneking M: Identification and analysis of genomic regions with large between-population differentiation in humans. Ann Hum Genet 2008, 72:99-110.

20. Schadt EE, Molony C, Chudin E, Hao K, Yang X, Lum PY, Kasarskis A, Zhang B, Wang S, Suver C, Zhu J, Millstein J, Sieberts S, Lamb J, GuhaThakurta D, Derry J, Storey JD, Avila-Campillo I, Kruger MJ, Johnson JM, Rohl CA, van Nas A, Mehrabian M, Drake TA, Lusis AJ, Smith RC, Guengerich FP, Strom SC, Schuetz E, Rushmore TH, et al: Mapping the genetic architecture of gene expression in human liver. PLoS Biol 2008, 6:e107.

21. Innocenti F, Cooper GM, Stanaway IB, Gamazon ER, Smith JD, Mirkov S, Ramirez J, Liu W, Lin YS, Moloney C, Aldred SF, Trinklein ND, Schuetz E, Nickerson DA, Thummel KE, Rieder MJ, Rettie AE, Ratain MJ, Cox NJ, Brown CD: Identification, replication, and functional fine-mapping of expression quantitative trait loci in primary human liver tissue. PLoS Genet 2011, 7:e1002078.

22. Stranger BE, Montgomery SB, Dimas AS, Parts L, Stegle O, Ingle CE, Sekowska M, Smith GD, Evans D, GutierrezArcelus M, Price A, Raj T, Nisbett J, Nica AC, Beazley C, Durbin R, Deloukas P, Dermitzakis ET: Patterns of cis regulatory variation in diverse human populations. PLoS Genet 2012, 8:e1002639.

23. Grundberg E, Small KS, Hedman ÅK, Nica AC, Buil A, Keildson S, Bell JT, Yang TP, Meduri E, Barrett A, Nisbett J, Sekowska M, Wilk A, Shin SY, Glass D, Travers M, Min JL, Ring S, Ho K, Thorleifsson G, Kong A, Thorsteindottir U, Ainali C, Dimas AS, Hassanali N, Ingle C, Knowles D, Krestyaninova M, Lowe CE, Di Meglio P, et al: Mapping cis- and trans-regulatory effects across multiple tissues in twins. Nat Genet 2012, 44:1084-1089.

24. Westra HJ, Peters MJ, Esko T, Yaghootkar H, Schurmann C, Kettunen J, Christiansen MW, Fairfax BP, Schramm K, Powell JE, Zhernakova A, Zhernakova DV, Veldink JH, Van den Berg LH, Karjalainen J, Withoff S, Uitterlinden AG, Hofman A, Rivadeneira F, 't Hoen PA, Reinmaa E, Fischer K, Nelis M, Milani L, Melzer D, Ferrucci L, Singleton AB, Hernandez DG, Nalls MA, Homuth G, et al: Systematic identification of trans eQTLs as putative drivers of known disease associations. Nat Genet 2013, 45:1238-1243.

25. Richardson $K$, Lai CQ, Parnell LD, Lee YC, Ordovas JM: A genome-wide survey for SNPs altering microRNA seed sites identifies functional candidates in GWAS. BMC Genomics 2011, 12:504

26. Lewis BP, Burge CB, Bartel DP: Conserved seed pairing, often flanked by adenosines, indicates that thousands of human genes are microRNA targets. Cell 2005, 120:15-20.

27. John B, Enright AJ, Aravin A, Tuschl T, Sander C, Marks DS: Human microRNA targets. PLoS Biol 2004, 2:e363.

28. Betel D, Koppal A, Agius P, Sander C, Leslie C: Comprehensive modeling of microRNA targets predicts functional non-conserved and non-canonical sites. Genome Biol 2010, 11:R90.

29. Kertesz M, lovino N, Unnerstall U, Gaul U, Segal E: The role of site accessibility in microRNA target recognition. Nat Genet 2007, 39:1278-1284.

30. Krek A, Grün D, Poy MN, Wolf R, Rosenberg L, Epstein EJ, MacMenamin P, da Piedade I, Gunsalus KC, Stoffel M, Rajewsky N: Combinatorial microRNA target predictions. Nat Genet 2005, 37:495-500. 
31. Thomas LF, Saito T, Sætrom P: 2011 Inferring causative variants in microRNA target sites. Nucleic Acids Res 2011, 39:e109.

32. Hariharan M, Scaria V, Brahmachari SK: dbSMR: a novel resource of genome-wide SNPs affecting microRNA mediated regulation. BMC Bioinformatics 2009, 10:108.

33. Bao L, Zhou M, Wu L, Lu L, Goldowitz D, Williams RW, Cui Y: PolymiRTS Database: linking polymorphisms in microRNA target sites with complex traits. Nucleic Acids Res 2007, 35:D51-D54.

34. Ziebarth JD, Bhattacharya A, Chen A, Cui Y: PolymiRTS Database 2.0: linking polymorphisms in microRNA target sites with human diseases and complex traits. Nucleic Acids Res 2012, 40:D216-D221.

35. Bhattacharya A, Ziebarth JD, Cui Y: PolymiRTS Database 3.0: linking polymorphisms in microRNAs and their target sites with human diseases and biological pathways. Nucleic Acids Res 2014, 42:D86-D91.

36. Hiard S, Charlier C, Coppieters W, Georges M, Baurain D: Patrocles: a database of polymorphic miRNA-mediated gene regulation in vertebrates. Nucleic Acids Res 2010, 38:D640-D651.

37. Conde L, Vaquerizas JM, Dopazo H, Arbiza L, Reumers J, Rousseau F, Schymkowitz J, Dopazo J: PupaSuite: finding functional single nucleotide polymorphisms for large-scale genotyping purposes. Nucleic Acids Res 2006, 34:W621-W625.

38. Bruno AE, Li L, Kalabus JL, Pan Y, Yu A, Hu Z: miRdSNP: a database of disease-associated SNPs and microRNA target sites on 3'UTRs of human genes. BMC Genomics 2012, 13:44

39. IGong J, Tong Y, Zhang HM, Wang K, Hu T, Shan G, Sun J, Guo AY: Genome-wide identification of SNPs in microRNA genes and the SNP effects on microRNA target binding and biogenesis. Hum Mutat 2012, 33:254-263.

40. Liu C, Zhang F, Li T, Lu M, Wang L, Yue W, Zhang D: MirSNP, a database of polymorphisms altering miRNA target sites, identifies miRNA-related SNPs in GWAS SNPs and eQTLs. BMC Genomics 2012, 13:661.

41. Jeggari A, Marks DS, Larsson E: miRcode: a map of putative microRNA target sites in the long non-coding transcriptome. Bioinformatics 2012, 28:2062-2063.

42. Clinical Genomic Database. [http://research.nhgri.nih.gov/CGD/download/]

43. Solomon BD, Nguyen AD, Bear KA, Wolfsberg TG: Clinical genomic database. Proc Natl Acad Sci U S A 2013, 110:9851-9855.

44. Manolio TA, Collins FS, Cox NJ, Goldstein DB, Hindorff LA, Hunter DJ, McCarthy MI, Ramos EM, Cardon LR, Chakravarti A, Cho JH, Guttmacher AE, Kong A, Kruglyak L, Mardis E, Rotimi CN, Slatkin M, Valle D, Whittemore AS, Boehnke M, Clark AG, Eichler EE, Gibson G, Haines JL, Mackay TF, McCarroll SA, Visscher PM: Finding the missing heritability of complex diseases. Nature 2009, 461:747-753.

45. Welter D, MacArthur J, Morales J, Burdett T, Hall P, Junkins H, Klemm A, Flicek P, Manolio T, Hindorff L, Parkinson H: The NHGRI GWAS Catalog, a curated resource of SNP-trait associations. Nucleic Acids Res 2014, 42:D1001-D1006.

46. Ramos EM, Hoffman D, Junkins HA, Maglott D, Phan L, Sherry ST, Feolo M, Hindorff LA: Phenotype-Genotype Integrator (PheGenl): synthesizing genome-wide association study (GWAS) data with existing genomic resources. Eur J Hum Genet 2014, 22:144-147.

47. Ganesh SK, Arnett DK, Assimes TL, Basson CT, Chakravarti A, Ellinor PT, Engler MB, Goldmuntz E, Herrington DM, Hershberger RE, Hong Y, Johnson JA, Kittner SJ, McDermott DA, Meschia JF, Mestroni L, O'Donnell CJ, Psaty BM, Vasan RS, Ruel M, Shen WK, Terzic A, Waldman SA, American Heart Association Council on Functional Genomics and Translational Biology; American Heart Association Council on Epidemiology and Prevention; American Heart Association Council on Basic Cardiovascular Sciences; American Heart Association Council on Cardiovascular Disease in the Young; American Heart Association Council on Cardiovascular and Stroke Nursing; American Heart Association Stroke Council: Genetics and genomics for the prevention and treatment of cardiovascular disease: update: a scientific statement from the American Heart Association. Circulation 2013, 128:2813-2851.

48. Turner SD, Berg RL, Linneman JG, Peissig PL, Crawford DC, Denny JC, Roden DM, McCarty CA, Ritchie MD, Wilke RA: Knowledge-driven multi-locus analysis reveals gene-gene interactions influencing HDL cholesterol level in two independent EMR-linked biobanks. PLoS One 2011, 6:e19586.

49. Ma L, Brautbar A, Boerwinkle E, Sing CF, Clark AG, Keinan A: Knowledge-driven analysis identifies a gene-gene interaction affecting high-density lipoprotein cholesterol levels in multi-ethnic populations. PLoS Genet 2012, 8:e1002714.

50. Skibola CF, Holly EA, Forrest MS, Hubbard A, Bracci PM, Skibola DR, Hegedus C, Smith MT: Body mass index, leptin and leptin receptor polymorphisms, and non-hodgkin lymphoma. Cancer Epidemiol Biomarkers Prev 2004, 13:779-786.

51. Park HS, Kim Y, Lee C: Single nucleotide variants in the beta2-adrenergic and beta3-adrenergic receptor genes explained $18.3 \%$ of adolescent obesity variation. J Hum Genet 2005, 50:365-369.

52. Sorli JV, Corella D, Francés F, Ramírez JB, González Jl, Guillén M, Portolés O: The effect of the APOE polymorphism on HDL-C concentrations depends on the cholesterol ester transfer protein gene variation in a Southern European population. Clin Chim Acta 2006, 366:196-203.

53. Isaacs A, Aulchenko YS, Hofman A, Sijbrands EJ, Sayed-Tabatabaei FA, Klungel OH, Maitland-van der Zee AH, Stricker BH, Oostra BA, Witteman JC, van Duijn CM: Epistatic effect of cholesteryl ester transfer protein and hepatic lipase on serum high-density lipoprotein cholesterol levels. J Clin Endocrinol Metab 2007, 92:2680-2687.

54. Alsaleh A, Frost GS, Griffin BA, Lovegrove JA, Jebb SA, Sanders TA, O'Dell SD, RISCK Study investigators: PPARY2 gene Pro12Ala and PPARa gene Leu162Val single nucleotide polymorphisms interact with dietary intake of fat in determination of plasma lipid concentrations. J Nutrigenet Nutrigenomics 2011, 4:354-366.

55. Mattei J, Parnell LD, Lai CQ, Garcia-Bailo B, Adiconis X, Shen J, Arnett D, Demissie S, Tucker KL, Ordovas JM: Disparities in allele frequencies and population differentiation for 101 disease-associated single nucleotide polymorphisms between Puerto Ricans and non-Hispanic whites. BMC Genet 2009, 10:45.

56. Chen R, Corona E, Sikora M, Dudley JT, Morgan AA, Moreno-Estrada A, Nilsen GB, Ruau D, Lincoln SE, Bustamante $C D$, Butte AJ: Type 2 diabetes risk alleles demonstrate extreme directional differentiation among human populations, compared to other diseases. PLoS Genet 2012, 8:e1002621.

57. Xu Y, Wang L, He J, Bi Y, Li M, Wang T, Wang L, Jiang Y, Dai M, Lu J, Xu M, Li Y, Hu N, Li J, Mi S, Chen CS, Li G, Mu Y, Zhao J, Kong L, Chen J, Lai S, Wang W, Zhao W, Ning G, for the 2010 China Noncommunicable Disease Surveillance Group: Prevalence and control of diabetes in Chinese adults. JAMA 2013, 310:948-959. 
58. Hancock AM, Witonsky DB, Gordon AS, Eshel G, Pritchard JK, Coop G, Di Rienzo A: Adaptations to climate in candidate genes for common metabolic disorders. PLoS Genet 2008, 4:e32.

59. Raj SM, Pagani L, Gallego Romero I, Kivisild T, Amos W: A general linear model-based approach for inferring selection to climate. BMC Genet 2013, 14:87.

60. Laland KN, Odling-Smee J, Myles S: How culture shaped the human genome: bringing genetics and the human sciences together. Nat Rev Genet 2010, 11:137-148.

61. Scheinfeldt LB, Soi S, Thompson S, Ranciaro A, Woldemeskel D, Beggs W, Lambert C, Jarvis JP, Abate D, Belay G, Tishkoff SA: Genetic adaptation to high altitude in the Ethiopian highlands. Genome Biol 2012, 13:R1.

62. Buroker NE, Ning XH, Zhou ZN, Li K, Cen WJ, Wu XF, Zhu WZ, Scott CR, Chen SH: AKT3, ANGPTL4, eNOS3, and VEGFA associations with high altitude sickness in Han and Tibetan Chinese at the Qinghai-Tibetan Plateau. Int J Hematol 2012, 96:200-213.

63. Weinberg RB: Apolipoprotein A-IV-2 allele: association of its worldwide distribution with adult persistence of lactase and speculation on its function and origin. Genet Epidemiol 1999, 17:285-297.

64. Keller KL: Genetic influences on oral fat perception and preference: Presented at the symposium "The Taste for Fat: New Discoveries on the Role of Fat in Sensory Perception, Metabolism, Sensory Pleasure and Beyond" held at the Institute of Food Technologists 2011 Annual Meeting, New Orleans, LA, June 12, 2011. J Food Sci 2012, 77:S143-S147.

65. Bains RK, Kovacevic M, Plaster CA, Tarekegn A, Bekele E, Bradman NN, Thomas MG: Molecular diversity and population structure at the Cytochrome P450 3A5 gene in Africa. BMC Genet 2013, 14:34.

66. Simonson TS, Yang Y, Huff CD, Yun H, Qin G, Witherspoon DJ, Bai Z, Lorenzo FR, Xing J, Jorde LB, Prchal JT, Ge R: Genetic evidence for high-altitude adaptation in Tibet. Science 2010, 329:72-75.

67. Udpa N, Ronen R, Zhou D, Liang J, Stobdan T, Appenzeller O, Yin Y, Du Y, Guo L, Cao R, Wang Y, Jin X, Huang C, Jia W, Cao D, Guo G, Claydon VE, Hainsworth R, Gamboa JL, Zibenigus M, Zenebe G, Xue J, Liu S, Frazer KA, Li Y, Bafna V, Haddad GG: Whole genome sequencing of Ethiopian highlanders reveals conserved hypoxia tolerance genes. Genome Biol 2014, 15:R36.

68. Hancock AM, Clark VJ, Qian Y, Di Rienzo A: Population genetic analysis of the uncoupling proteins supports a role for UCP3 in human cold resistance. Mol Biol Evol 2011, 28:601-614.

69. Simonson TS, McClain DA, Jorde LB, Prchal JT: Genetic determinants of Tibetan high-altitude adaptation. Hum Genet 2012, 131:527-533.

70. Hashimoto T, Yokokawa T, Endo Y, Iwanaka N, Higashida K, Taguchi S: Modest hypoxia significantly reduces triglyceride content and lipid droplet size in 3 T3-L1 adipocytes. Biochem Biophys Res Commun 2013, 440:43-49.

71. Rosenow A, Noben JP, Bouwman FG, Mariman EC, Renes J: Hypoxia-mimetic effects in the secretome of human preadipocytes and adipocytes. Biochim Biophys Acta 1834, 2013:2761-2771.

72. Levinson RS, Yi CX, Zeltser L, Tschöp M, Kahn CR, Accili D, Kulkarni R, Mirmira RG, Lee HY, Shulman GI, Scherer PE, Nguyen KD, Chawla A: Metabolic Syndrome ePoster. Nat Med 2011, 17. http://www.nature.com/nm/e-poster/ eposter_full.html.

73. Laayouni H, Oosting M, Luisi P, loana M, Alonso S, Ricaño-Ponce I, Trynka G, Zhernakova A, Plantinga TS, Cheng SC, van der Meer JW, Popp R, Sood A, Thelma BK, Wijmenga C, Joosten LA, Bertranpetit J, Netea MG: Convergent evolution in European and Rroma populations reveals pressure exerted by plague on Toll-like receptors. Proc Natl Acad Sci U S A 2014, 111:2668-2673.

74. Penas-Steinhardt A, Barcos LS, Belforte FS, de Sereday M, Vilariño J, Gonzalez CD, Martínez-Larrad MT, Tellechea ML, Serrano-Ríos M, Poskus E, Frechtel GD, Leskow FC: Functional characterization of TLR4 + 3725 G/C polymorphism and association with protection against overweight. PLOS One 2012, 7:e50992.

75. Khrameeva EE, Bozek K, He L, Yan Z, Jiang X, Wei Y, Tang K, Gelfand MS, Prüfer K, Kelso J, Pääbo S, Giavalisco P, Lachmann M, Khaitovich P: Neanderthal ancestry drives evolution of lipid catabolism in contemporary Europeans. Nat Commun 2014, 5:3584.

76. Kim J, Lee T, Lee HJ, Kim H: Genotype-environment interactions for quantitative traits in Korea Associated Resource (KARE) cohorts. BMC Genet 2014, 15:18.

77. Patel CJ, Rehkopf DH, Leppert JT, Bortz WM, Cullen MR, Chertow GM, loannidis JP: Systematic evaluation of environmental and behavioural factors associated with all-cause mortality in the United States National Health and Nutrition Examination Survey. Int J Epidemiol 2013, 42:1795-1810.

78. Pasquali L, Gaulton KJ, Rodríguez-Seguí SA, Mularoni L, Miguel-Escalada I, Akerman I, Tena JJ, Morán I, Gómez-Marín C, van de Bunt M, Ponsa-Cobas J, Castro N, Nammo T, Cebola I, García-Hurtado J, Maestro MA, Pattou F, Piemonti L, Berney T, Gloyn AL, Ravassard P, Skarmeta JL, Müller F, McCarthy MI, Ferrer J: Pancreatic islet enhancer clusters enriched in type 2 diabetes risk-associated variants. Nat Genet 2014, 46:136-143.

79. Heneghan HM, Miller N, Kerin MJ: Role of microRNAs in obesity and the metabolic syndrome. Obes Rev 2010, 11:354-361.

80. Moore KJ, Rayner KJ, Suárez Y, Fernández-Hernando C: The role of microRNAs in cholesterol efflux and hepatic lipid metabolism. Annu Rev Nutr 2011, 31:49-63.

81. Kim J, Bartel DP: Allelic imbalance sequencing reveals that single-nucleotide polymorphisms frequently alter microRNA-directed repression. Nat Biotechnol 2009, 27:472-477.

82. Gamazon ER, Ziliak D, Im HK, LaCroix B, Park DS, Cox NJ, Huang RS: Genetic architecture of microRNA expression: implications for the transcriptome and complex traits. Am J Hum Genet 2012, 90:1046-1063.

83. Lu J, Clark AG: Impact of microRNA regulation on variation in human gene expression. Genome Res 2012, 22:1243-1254.

84. Shoemaker R, Deng J, Wang W, Zhang K: Allele-specific methylation is prevalent and is contributed by CpG-SNPs in the human genome. Genome Res 2010, 20:883-889.

85. Zhi D, Aslibekyan S, Irvin MR, Claas SA, Borecki IB, Ordovas JM, Absher DM, Arnett DK: SNPs located at CpG sites modulate genome-epigenome interaction. Epigenetics 2013, 8:802-806.

86. van Vliet-Ostaptchouk JV, Snieder H, Lagou V: Gene-lifestyle interactions in obesity. Curr Nutr Rep 2012, 1:184-196. 
87. Dayeh T, Volkov P, Salö S, Hall E, Nilsson E, Olsson AH, Kirkpatrick CL, Wollheim CB, Eliasson L, Rönn T, Bacos K Ling C: Genome-wide DNA methylation analysis of human pancreatic islets from type 2 diabetic and nondiabetic donors identifies candidate genes that influence insulin secretion. PLoS Genet 2014, 10:e1004160.

88. Björkegren JL, Hägg S, Talukdar HA, Foroughi Asl H, Jain RK, Cedergren C, Shang MM, Rossignoli A, Takolander R, Melander O, Hamsten A, Michoel T, Skogsberg J: Plasma cholesterol-induced lesion networks activated before regression of early, mature, and advanced atherosclerosis. PLoS Genet 2014, 10:e1004201.

89. Moore $\mathrm{JH}$ : From genotypes to genometypes: putting the genome back in genome-wide association studies. Eur J Hum Genet 2009, 17:1205-1206.

90. Casas-Agustench P, Arnett DK, Smith CE, Lai CQ, Parnell LD, Borecki IB, Frazier-Wood AC, Allison M, Chen YD, Taylor KD, Rich SS, Rotter JI, Lee YC, Ordovás JM: Saturated fat intake modulates the association between an obesity genetic risk score and body mass index in two US populations. J Acad Nutr Diet. in press.

91. Zheng JS, Lai CQ, Parnell LD, Lee YC, Shen J, Smith CE, Casas-Agustench P, Richardson K, Li D, Noel SE, Tucker KL, Arnett DK, Borecki IB, Ordovás JM: Genome-wide interaction of genotype by erythrocyte $\mathrm{n}-3$ fatty acids contributes to phenotypic variance of diabetes-related traits. BMC Genomics 2014, 15:781.

doi:10.1186/1756-0381-7-21

Cite this article as: Parnell et al:: CardioGxE, a catalog of gene-environment interactions for cardiometabolic traits. BioData Mining 2014 7:21.

\section{Submit your next manuscript to BioMed Central and take full advantage of:}

- Convenient online submission

- Thorough peer review

- No space constraints or color figure charges

- Immediate publication on acceptance

- Inclusion in PubMed, CAS, Scopus and Google Scholar

- Research which is freely available for redistribution

Submit your manuscript at www.biomedcentral.com/submit

() Biomed Central 